Check for updates

Cite this: RSC Adv., 2019, 9, 20652

\title{
Synthesis and biological evaluation of an epidermal growth factor receptor-targeted peptide- conjugated phthalocyanine-based photosensitiser $\uparrow$
}

\author{
Evelyn Y. Xue, ${ }^{a}$ Roy C. H. Wong, ${ }^{a}$ Clarence T. T. Wong, ${ }^{a}$ Wing-Ping Fong ${ }^{b}$ \\ and Dennis K. P. Ng (DD *a
}

A peptide-conjugated zinc(II) phthalocyanine containing the epidermal growth factor receptor-targeted heptapeptide QRHKPRE has been prepared. The conjugate labelled as $\mathrm{ZnPc}-\mathrm{QRH}{ }^{*}$ can selectively bind to the cell membrane of HT29 human colorectal adenocarcinoma cells in 10 min followed by internalisation upon prolonged incubation via receptor-mediated endocytosis, leading to localisation in lysosomes eventually. By manipulating the incubation time, the subcellular localisation of the conjugate can be varied and the cell-death pathways induced upon irradiation can also be altered. It has been found that photosensitisation initiated at the cell membrane and in the lysosomes would trigger cell death mainly through necrosis and apoptosis respectively. Intravenous administration of the conjugate into HT29 tumour-bearing nude mice resulted in higher accumulation in the tumour than in most major organs. The selective binding of this conjugate to tumour has also been demonstrated by comparing the results with those of the analogue with a scrambled peptide sequence (EPRQRHK). The overall results indicate that $\mathrm{ZnPc}-\mathrm{QRH}^{*}$ is a promising EGFR-targeted photosensitiser for photodynamic therapy.

\author{
Received 24th May 2019 \\ Accepted 21st June 2019 \\ DOI: 10.1039/c9ra03911b \\ rsc.li/rsc-advances
}

\section{Introduction}

Multifunctional theranostic agents for simultaneous imaging and eradication of tumours have received considerable interest. ${ }^{\mathbf{1}}$ Various non-invasive imaging techniques have been used in combination with a range of therapeutic modalities for imageguided therapy. In particular, the combination of fluorescence imaging and photodynamic therapy (PDT) has gained growing attention in recent years. ${ }^{2}$ PDT is a clinically established treatment modality for a range of superficial and localised cancers, as well as certain non-cancerous conditions, such as wet age-related macular degeneration. ${ }^{3}$ Its application in photo-eradication of microbials has also been actively explored. ${ }^{4}$ The treatment involves the action of a photosensitiser, light of an appropriate wavelength and oxygen to induce cytotoxicity via the generation of reactive oxygen species (ROS), such as singlet oxygen. These ROS destroy tumours by multiple mechanisms, including killing malignant cells by apoptosis and/or necrosis, shutting down the tumour vasculature and stimulating the host immune system. ${ }^{5}$ Compared with the traditional therapeutic methods, such as chemotherapy, radiotherapy and surgery, PDT has several potential advantages.

${ }^{a}$ Department of Chemistry, The Chinese University of Hong Kong, Shatin, N.T., Hong Kong, China.E-mail: dkpn@cuhk.edu.hk

${ }^{b}$ School of Life Sciences, The Chinese University of Hong Kong, Shatin, N.T., Hong Kong, China

† Electronic supplementary information (ESI) available. See DOI: 10.1039/c9ra03911b
Generally, it is non-invasive and has tolerance of repeated doses, few side effects and high specificity that can be achieved through precise delivery of light. Apart from ROS generation, most of the photosensitisers can also emit fluorescence upon excitation. A balance of these two competitive photochemical and photophysical pathways is important in order to achieve these dual functions. Among the various classes of photosensitisers, such as porphyrins, chlorins, boron dipyrromethenes, indocyanines, aggregation-induced emission dyes and phthalocyanines, ${ }^{6}$ the last group of functional dyes are particular attractive for fluorescenceguided PDT due to their high ROS generation efficiency and relatively strong fluorescence emission, as well as strong absorption in the red visible region that allows deep tissue penetration, high photostability and ease of chemical and physical modifications. ${ }^{7}$ To date, a vast number of phthalocyanine-based photosensitisers have been reported, and a few of them have been in clinical use (e.g. Photosens $\left.{ }^{\circledR}\right)$ or in clinical trial (e.g. Pc 4, CGP55847 and Photocyanine) for PDT of a range of cancers.

One of the drawbacks of phthalocyanines for this application is their poor water solubility and strong aggregation tendency that largely quench their fluorescence emission and ROS generation. ${ }^{7 b}$ To circumvent this problem, various nanoplatforms, such as liposomes, polymeric micelles, gold nanoparticles and mesoporous silica nanoparticles have been used to encapsulate or adsorb phthalocyanines for delivery and maintaining their photoactivities. ${ }^{8}$ Alternatively, various bulky and hydrophilic moieties have been introduced, among which tumour-homing peptides are particularly attractive. ${ }^{9}$ These biomolecules not only can enhance 
the water solubility of the hydrophobic macrocycles, but also can deliver the photosensitisers to tumour site selectively via receptormediated endocytosis. We have been interested in exploring peptide-conjugated phthalocyanine-based photosensitisers for targeting colonic adenocarcinomas. ${ }^{\mathbf{1 0}}$ Colorectal cancer (CRC) is one of the most common causes of cancer-related mortality worldwide. ${ }^{\mathbf{1 1}}$ It typically develops over several years in a linear fashion from adenomatous polyps to carcinomas. Routine colon screening, detection and removal of polyp adenomas at an early stage reduce the incidence of CRC. However, as the disease lacks outward signs or symptoms, most of the cases are detected at a terminal stage. Therefore, early detection and treatment of premalignant lesions are extremely important. Among the various CRC-targeting peptides that have been identified in recent years, ${ }^{12}$ the heptapeptide QRHKPRE can target the epidermal growth factor receptor (EGFR), which is overexpressed in a variety of human cancer cells, including colonic adenocarcinomas, and can bind specifically to the target cells within a few minutes that can facilitate the bioimaging. ${ }^{12 e}$ In fact, EGFR is a validated biomarker for CRC. ${ }^{13}$ We report herein a novel zinc(II) phthalocyanine conjugated with this peptide sequence, including the synthesis, characterisation, in vitro response against a range of EGFR-positive and negative cell lines, as well as in vivo tumour-localisation property.

\section{Results and discussion}

\section{Synthesis and characterisation}

The peptide-phthalocyanine conjugate (compound 4) was prepared according to Scheme 1. The linear peptide QRHKPRE was first linked to the non-functional glycine-serine-lysine GGGGSK spacer by using standard 9-fluorenylmethyloxycarbonyl
(Fmoc)-mediated solid-phase synthesis. The lysine at the Cterminal was incorporated as Fmoc-Lys(Mtt)-OH (Mtt $=4$-methyltrityl), and the Mtt protecting group in peptide 1 was removed with $1 \%$ trifluoroacetic acid (TFA) in $\mathrm{CH}_{2} \mathrm{Cl}_{2}$ in the presence of $2 \%$ triisopropylsilane (TIPS). The resulting peptide 2 was then coupled with the previously reported carboxy phthalocyanine $3^{14}$ on resin overnight in the presence of 1 -[bis(dimethylamino)methylene]- $1 \mathrm{H}$ 1,2,3-triazolo[4,5- $b]$ pyridinium 3-oxid hexafluorophosphate (HATU) and $N, N$-diisopropylethylamine (DIPEA). It was followed by removal of the Fmoc protecting group using $20 \%$ piperidine in $\mathrm{N}, \mathrm{N}$-dimethylformamide (DMF) and cleavage from the resin with a mixture of TFA/TIPS/ $\mathrm{H}_{2} \mathrm{O}(95: 2.5: 2.5$, v/v/v). The target conjugate 4 substituted with the sequence QRHKPREGGGGSK, hereafter labelled as $\mathrm{QRH}^{*}$, was purified with high-performance liquid chromatography (HPLC) and characterised with matrix-assisted laser desorption/ionisation time-of-flight (MALDI-TOF-MS) mass spectrometry (Fig. S1, ESI $\dagger$ ). To confirm the targeting effect of the QRHKPRE sequence, an analogue with a scrambled sequence (EPRQRHKGGGGSK, hereafter labelled as EPR*) (conjugate 5, structure not shown) was also prepared for comparison and characterised similarly (Fig. S2, ESI $\dagger$ ). With a number of polar and charged amino acid residues, both conjugates possessed good solubility in polar organic solvents and aqueous media.

\section{Spectroscopic and photophysical properties}

The electronic absorption and fluorescence spectra of ZnPc-QRH* (4) were recorded in DMF and phosphate buffered saline (PBS) with $0.01 \%$ Tween 80 (v/v). As shown in Fig. S3 (ESI $\dagger$ ), the conjugate gave an intense and sharp Q band at $672 \mathrm{~nm}$ (in DMF) or $680 \mathrm{~nm}$ (in PBS), showing that it was soluble and remained nonaggregated in both media as a result of the hydrophilic peptide
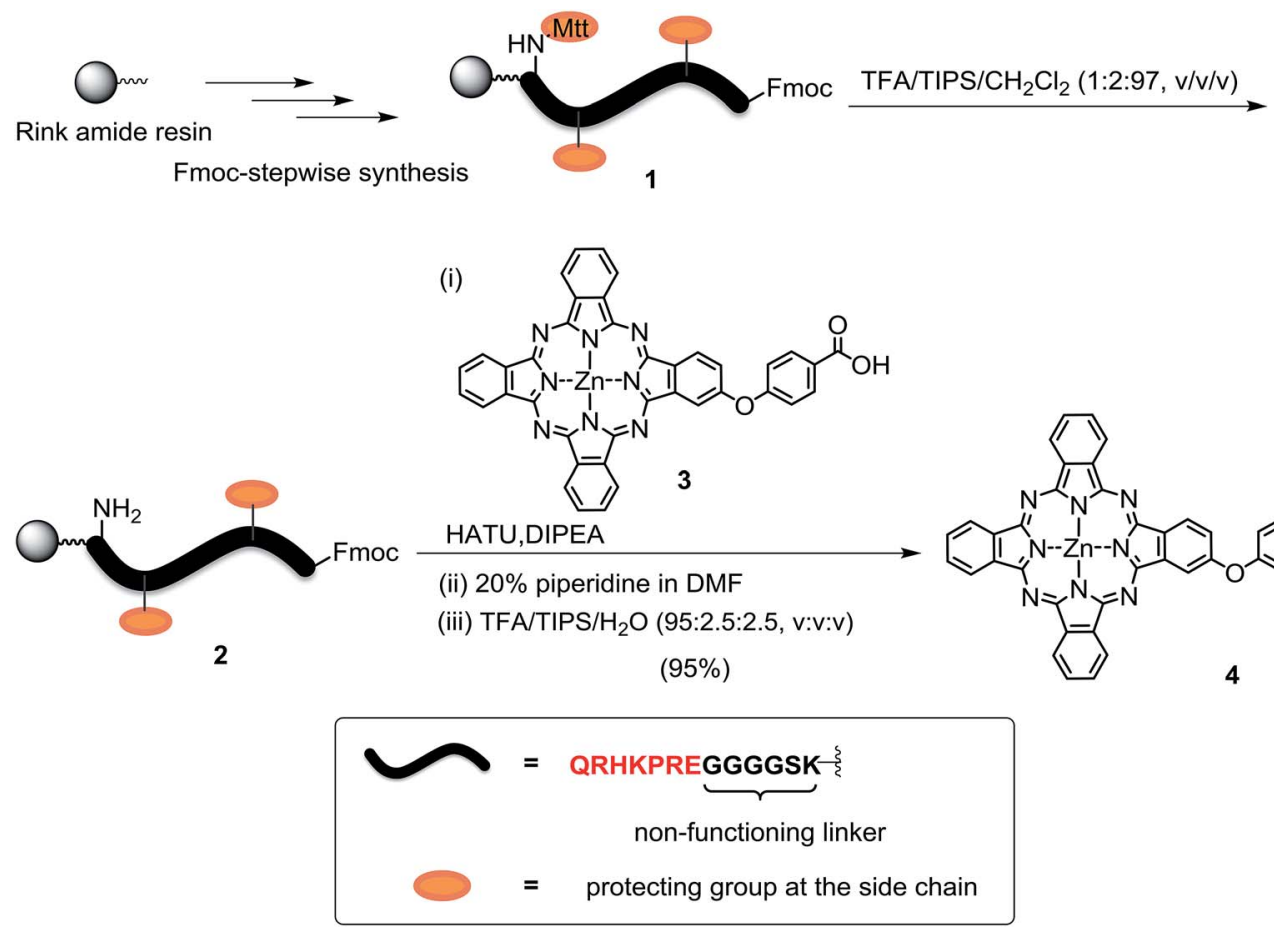

Scheme 1 Synthesis of conjugate $\mathrm{ZnPc}-\mathrm{QRH}^{*}$ (4). 
chain. Upon excitation at $610 \mathrm{~nm}$, the conjugate showed a fluorescence emission at $c a .680 \mathrm{~nm}$. The fluorescence quantum yield $\left(\Phi_{\mathrm{F}}\right)$ in DMF was determined to be 0.24 relative to the unsubstituted zinc(II) phthalocyanine $(\mathrm{ZnPc})\left(\Phi_{\mathrm{F}}=0.28\right) .{ }^{15}$ To determine the singlet oxygen generation efficiency, 1,3-diphenylisobenzofuran (DPBF) was used as the singlet oxygen scavenger. Conjugate 4 could induce photodegradation of DPBF in both media. Based on the rate of decrease in its absorbance at $417 \mathrm{~nm}$, the singlet oxygen quantum yield $\left(\Phi_{\Delta}\right)$ was determined to be 0.62 in DMF, which was slightly higher than that of $\operatorname{ZnPc}\left(\Phi_{\Delta}=0.56\right) .{ }^{16}$ Both the values of $\Phi_{\mathrm{F}}$ and $\Phi_{\Delta}$ of the mono- $\beta$-substituted 4 were also higher than those of our previously reported di- $\alpha$-substituted analogue substituted with another EGFR-targeted peptide GE11 (GYHWYGYTPQNVI) $\left(\Phi_{\mathrm{F}}=0.10, \Phi_{\Delta}=0.48\right) .{ }^{17}$ As expected, the spectral properties and singlet oxygen generation efficiency of the scrambled analogue ZnPc-EPR* (5) were very similar to those of 4 . Table 1 summarises the data in DMF for the two conjugates, and Fig. S4 (ESI $\dagger$ ) shows that the two conjugates have virtually the same efficiency in generating singlet oxygen for degradation of DPBF.

\section{Cellular uptake and subcellular localisation}

The cellular uptake of ZnPc-QRH* (4) by HT29 human colorectal adenocarcinoma cells was investigated using confocal laser scanning microscopy. Fig. 1 shows the time-dependent uptake process of conjugate 4 . It can be seen that fluorescence rings

Table 1 Spectroscopic and photophysical data of conjugates 4 and 5 in DMF

\begin{tabular}{llccc}
\hline & $\lambda_{\mathrm{abs}}(\mathrm{nm})(\log \varepsilon)$ & $\lambda_{\mathrm{em}}{ }^{a}$ & $\Phi_{\mathrm{F}}{ }^{b}$ & $\Phi_{\Delta}{ }^{c}$ \\
\hline ZnPc-QRH $^{*}(4)$ & $340(4.49), 607(4.27), 672(5.07)$ & 680 & 0.24 & 0.62 \\
ZnPc-EPR $^{*}(5)$ & $340(4.47), 607(4.28), 672(5.08)$ & 680 & 0.25 & 0.63 \\
${ }^{a}$ Excited at $610 \mathrm{~nm}^{b}{ }^{b}$ Relative to ZnPc in DMF $\left(\Phi_{\mathrm{F}}=0.28\right) .{ }^{c}$ Relative to \\
ZnPc in DMF $\left(\Phi_{\Delta}=0.56\right)$.
\end{tabular}

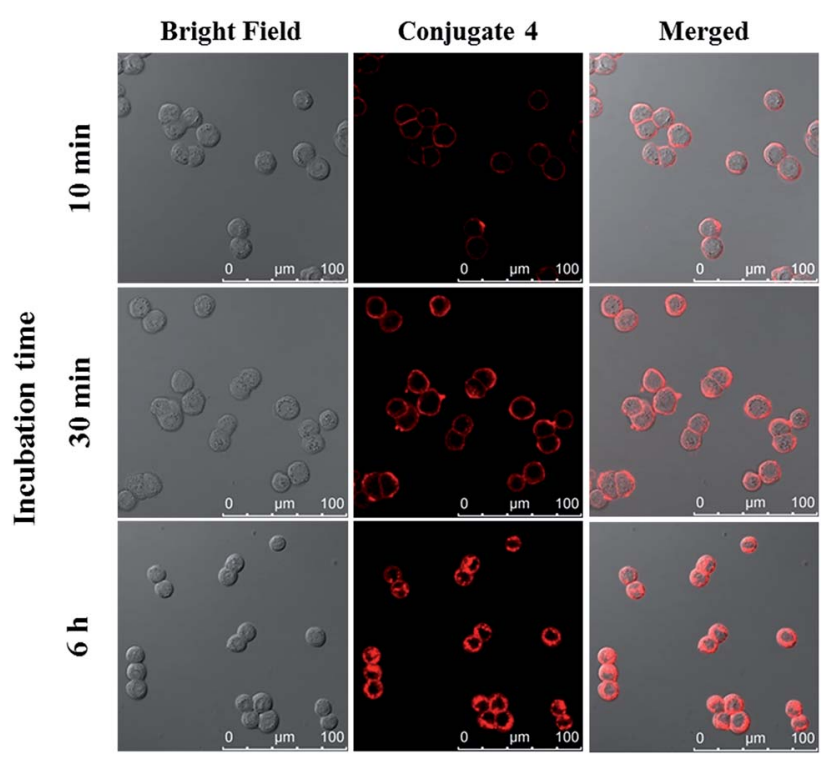

Fig. 1 Bright field, fluorescence and merged images of HT29 cells after incubation with conjugate $4(4 \mu \mathrm{M})$ for $10 \mathrm{~min}, 30 \mathrm{~min}$ and $6 \mathrm{~h}$ respectively. appear in 10 min showing that $\mathbf{4}$ binds to the cell membrane in a short period of time. It was then gradually internalised into the cells after $30 \mathrm{~min}$ and the internalisation became more significant after incubation for $6 \mathrm{~h}$. To confirm whether conjugate 4 was internalised into the cells by endocytosis, the cellular uptake of 4 was monitored at two different temperatures. HT29 cells were first incubated with $4(2 \mu \mathrm{M})$ for $10 \mathrm{~min}$ at $37^{\circ} \mathrm{C}$. After washing with PBS for three times, the cells were further incubated in a drug-free medium for a further $6 \mathrm{~h}$ at $4{ }^{\circ} \mathrm{C}$ or $37^{\circ} \mathrm{C}$. As shown in Fig. 2, after incubation with 4 for $10 \mathrm{~min}$, the conjugate remained on the cell membrane as indicated by its fluorescence. However, after further incubation for $6 \mathrm{~h}$ at $37^{\circ} \mathrm{C}$, the drug on the cell membrane was internalised and caused a 3 -fold increase in the intracellular fluorescence (Fig. S5, ESI $\dagger$ ). The increase in intracellular fluorescence intensity is believed to be caused by the partial quenching of the fluorescence of 4 on the cell membrane which was restored after internalisation. Hence, in the following experiments, the cells were all further incubated in a drug-free medium for a further $6 \mathrm{~h}$ after a $10 \mathrm{~min}$ drug incubation to avoid unintended fluorescence quenching. By contrast, for the case of post-incubation at $4{ }^{\circ} \mathrm{C}$, the fluorescence images were not significantly changed, showing that internalisation was not significant (Fig. 2). The results suggest that the internalisation of 4 into HT29 cells is mainly through endocytosis.

The subcellular localisation of $\mathbf{4}$ was further examined under the condition of incubation with $4(2 \mu \mathrm{M})$ for $10 \mathrm{~min}$ and then in a drug-free medium for a further $6 \mathrm{~h}$ at $37^{\circ} \mathrm{C}$. The cells were then stained with LysoTracker Green DND-26, MitoTracker Green FM or ER-Tracker green before being

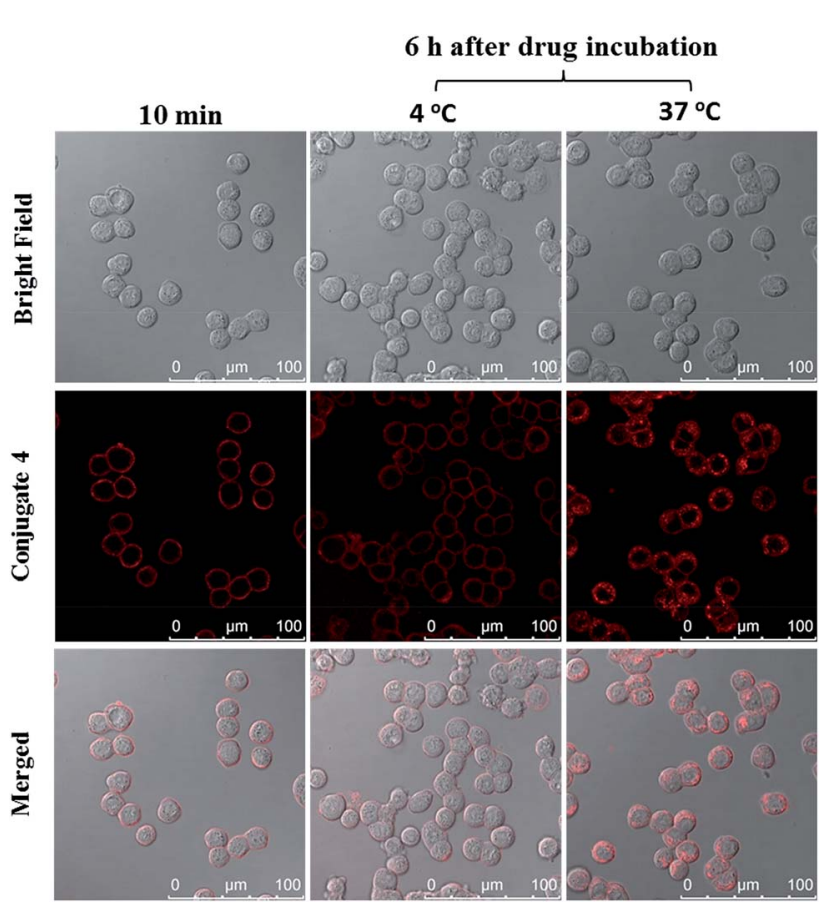

Fig. 2 Bright-field, fluorescence and merged images of HT29 cells after incubation with conjugate $4(2 \mu \mathrm{M})$ for $10 \mathrm{~min}$, and then the cells were further incubated in a drug-free medium for a further $6 \mathrm{~h}$ at $4{ }^{\circ} \mathrm{C}$ or $37^{\circ} \mathrm{C}$ 

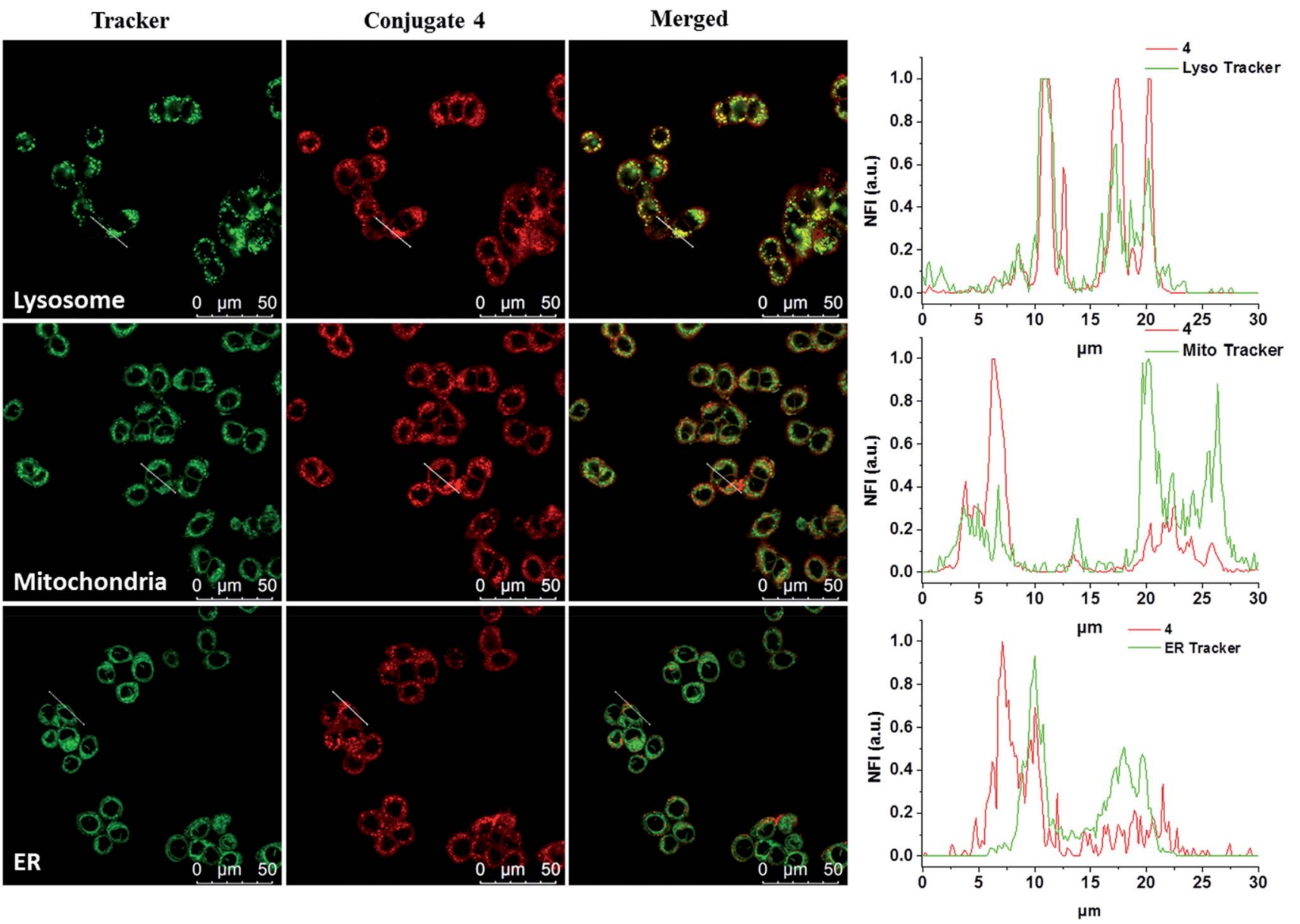

Fig. 3 Visualisation of the intracellular fluorescence of conjugate 4 and various subcellular trackers, as well as their overlapped images. The cells were first incubated with 4 for $10 \mathrm{~min}$, and then in a drug-free medium for $6 \mathrm{~h}$ at $37^{\circ} \mathrm{C}$. They were then further incubated with LysoTracker Green DND-26 $(2 \mu \mathrm{M})$, MitoTracker Green FM $(0.2 \mu \mathrm{M})$ or ER-Tracker green $(0.2 \mu \mathrm{M})$ for 15,15 and 30 min respectively at $37^{\circ} \mathrm{C}$. The right column shows the fluorescence intensity profiles of 4 and the trackers traced along the white lines in the corresponding images on the left.

a)

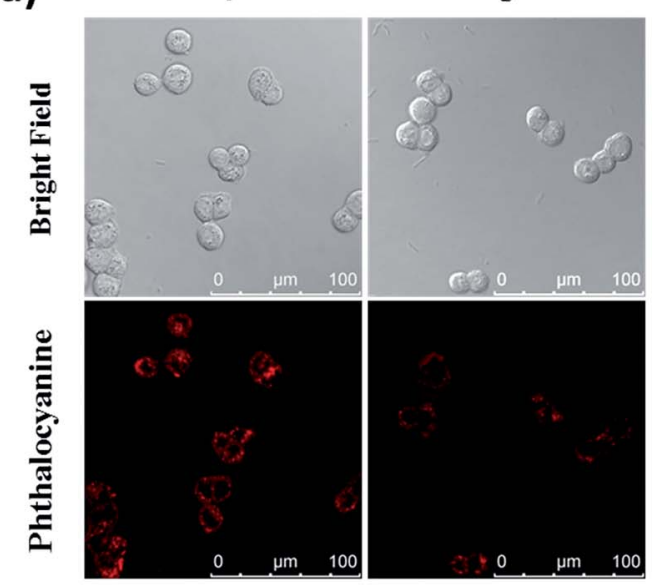

b)

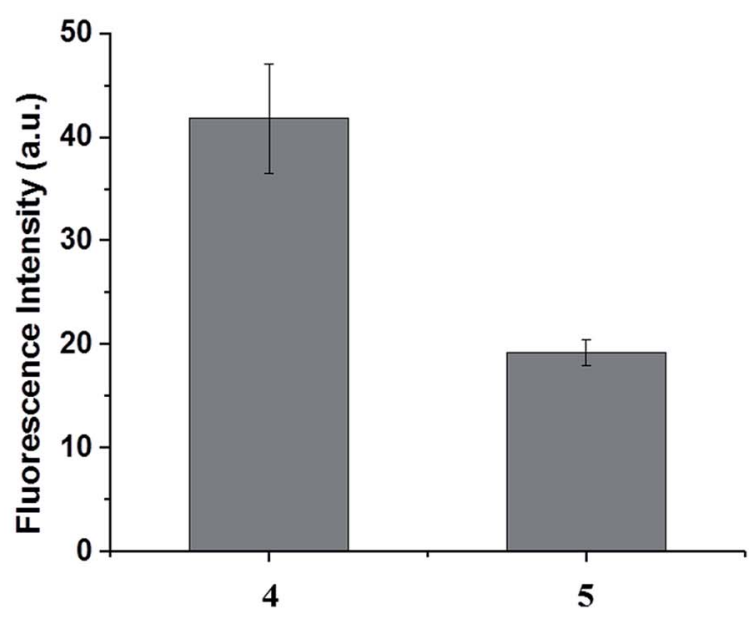

Fig. 4 (a) Bright-field and fluorescence images of HT29 cells after incubation with conjugate 4 or 5 ( $2 \mu \mathrm{M})$ for 10 min, followed by incubation in a drug-free medium for $6 \mathrm{~h}$. (b) The corresponding quantified fluorescence intensities. Data are expressed as the mean \pm standard error of the mean (SEM) of three independent experiments. 


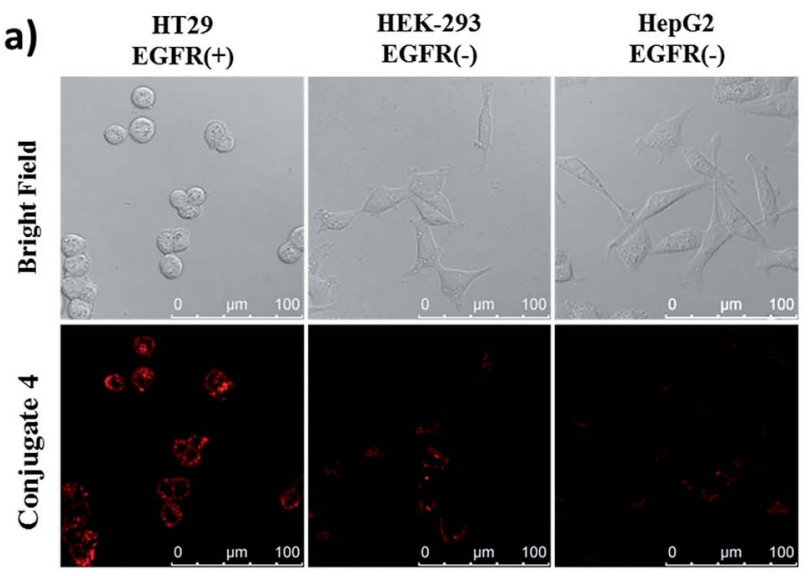

b)

Fig. 5 (a) Bright-field and fluorescence images of HT29, HEK-293 and HepG2 cells after incubation with conjugate 4 ( $2 \mu \mathrm{M})$ for 10 min, followed by incubation in a drug-free medium for $6 \mathrm{~h}$. (b) The corresponding quantified fluorescence intensities. Data are expressed as the mean $\pm \mathrm{SEM}$ of three independent experiments.

examined with a confocal laser scanning microscope. As shown in Fig. 3, the line profile of the fluorescence intensity of 4 overlaps well with that of LysoTracker Green, but not for the other two trackers, suggesting that the dye is localised mainly in lysosomes, which is the last compartment of the endocytic pathway after internalisation. This result is also consistent with the proposed receptor-mediated endocytosis mechanism.

\section{In vitro specific binding towards HT29 cells}

The specific binding of conjugate 4 towards HT29 cells was first validated by competitive inhibition with free $\mathrm{QRH} *$ peptide. The cells were pre-incubated with free $\mathrm{QRH}^{*}$ at various concentrations (up to $1 \mathrm{mM}$ ) for $30 \mathrm{~min}$ at $37^{\circ} \mathrm{C}$. They were then washed with PBS and then incubated further with conjugate $4(2 \mu \mathrm{M})$ for $10 \mathrm{~min}$, followed by incubation in a drug-free medium for $6 \mathrm{~h}$. It was found that upon pre-incubation with the free peptide, the intracellular fluorescence intensity decreased as the concentration of the peptide increased (Fig. S6, ESI $\dagger$ ). The results indicate that it is the peptide rather than the phthalocyanine unit that binds to the surface of HT29 cells.

To determine whether the binding of this peptide to HT29 cells was sequence specific, we selected a scrambled sequence (EPR*) for comparison. HT29 cells were incubated with ZnPc$\mathrm{QRH}^{*}$ (4) or ZnPc-EPR* (5) for $10 \mathrm{~min}$, followed by incubation in a drug-free medium for $6 \mathrm{~h}$. As shown in Fig. 4, the intracellular fluorescence intensity for $\mathbf{4}$ was about 2 -fold of that for $\mathbf{5}$. Although the difference is not very substantial, it is worth noting that the scrambled peptide also contains the same amino acids, which may still form similar secondary structure that can bind to the receptor to some extent. It has also been reported earlier that for the QRH*-conjugated Cy5.5, its intracellular fluorescence intensity is also only about 2 -fold of that for the scrambled control against HT29 and SW480 human colon adenocarcinoma cells, which have high and medium EGFR expression respectively. ${ }^{12 e}$ The difference in uptake as shown in Fig. 4 shows a high binding affinity of QRH* towards HT29 cells.
Apart from these studies, we also investigated whether QRH* $^{*}$ shows different affinity towards cancer cells with different expression levels of EGFR. Hence, we compared the cellular uptake of conjugate 4 towards HT29 cells, HEK-293 human embryonic kidney cells and HepG2 human hepatocellular carcinoma cells. The latter two were reported to express a low level of EGFR. ${ }^{18}$ These three kinds of cells were first incubated with $\mathbf{4}$ for $10 \mathrm{~min}$, followed by incubation in a drug-free medium for $6 \mathrm{~h}$. As shown in Fig. 5, the intracellular fluorescence intensity of 4 in HT29 cells was significantly higher than those in HEK-293 and HepG2 cells by about $4-$ and 6 -fold respectively. These results provide further evidence for the EGFR-targeting property of conjugate 4.

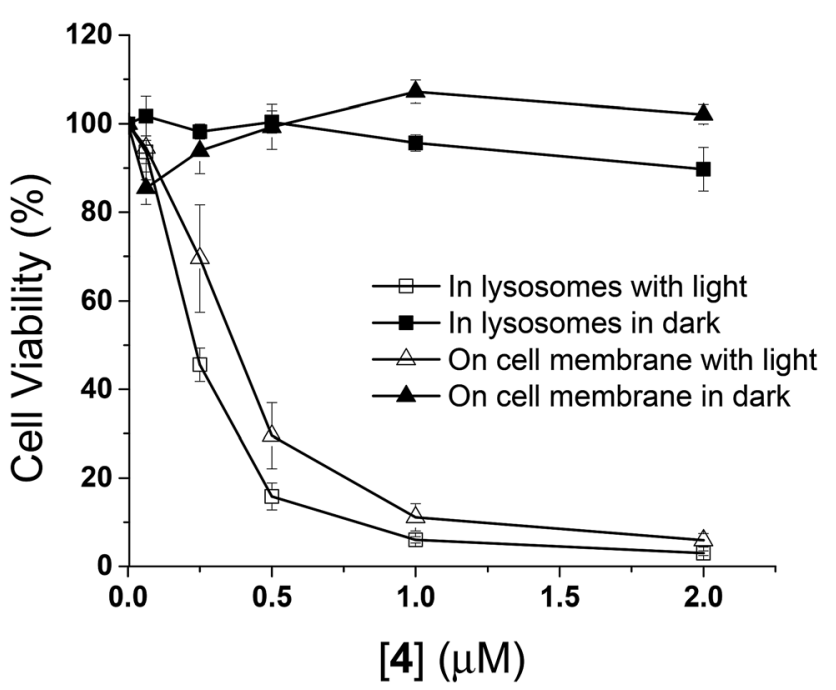

Fig. 6 Comparison of the cytotoxic effects of conjugate 4 on the cell membrane (triangles) and in lysosomes (squares) of HT29 cells in the absence (closed symbols) and presence (open symbols) of light ( $\lambda>$ $610 \mathrm{~nm}, 18 \mathrm{~mW} \mathrm{~cm}^{-2}, 22 \mathrm{~J} \mathrm{~cm}^{-2}$ ). Data are expressed as the mean \pm SEM of three independent experiments, each performed in quadruplicate. 


\section{In vitro photodynamic activities}

The in vitro photodynamic activities of conjugate 4 were then studied against HT29 cells. As mentioned above, when HT29 cells were incubated with $4(2 \mu \mathrm{M})$ for $10 \mathrm{~min}$, the drug was mainly confined on the cell surface, and internalisation occurred leading to localisation mainly in lysosomes after incubation in a drug-free medium for $6 \mathrm{~h}$. In order to examine if the photocytotoxicity is different when the PDT action is initiated at the cell membrane and in the lysosomes, the cell viabilities were measured by MTT assay $[\mathrm{MTT}=3-(4,5-$ dimethylthiazol-2-yl)-2,5-diphenyltetrazolium bromide] under these two conditions, both in the absence and presence of light irradiation. As shown in Fig. 6, while conjugate 4 did not show significant dark toxicity towards HT29 cells, it exhibited high

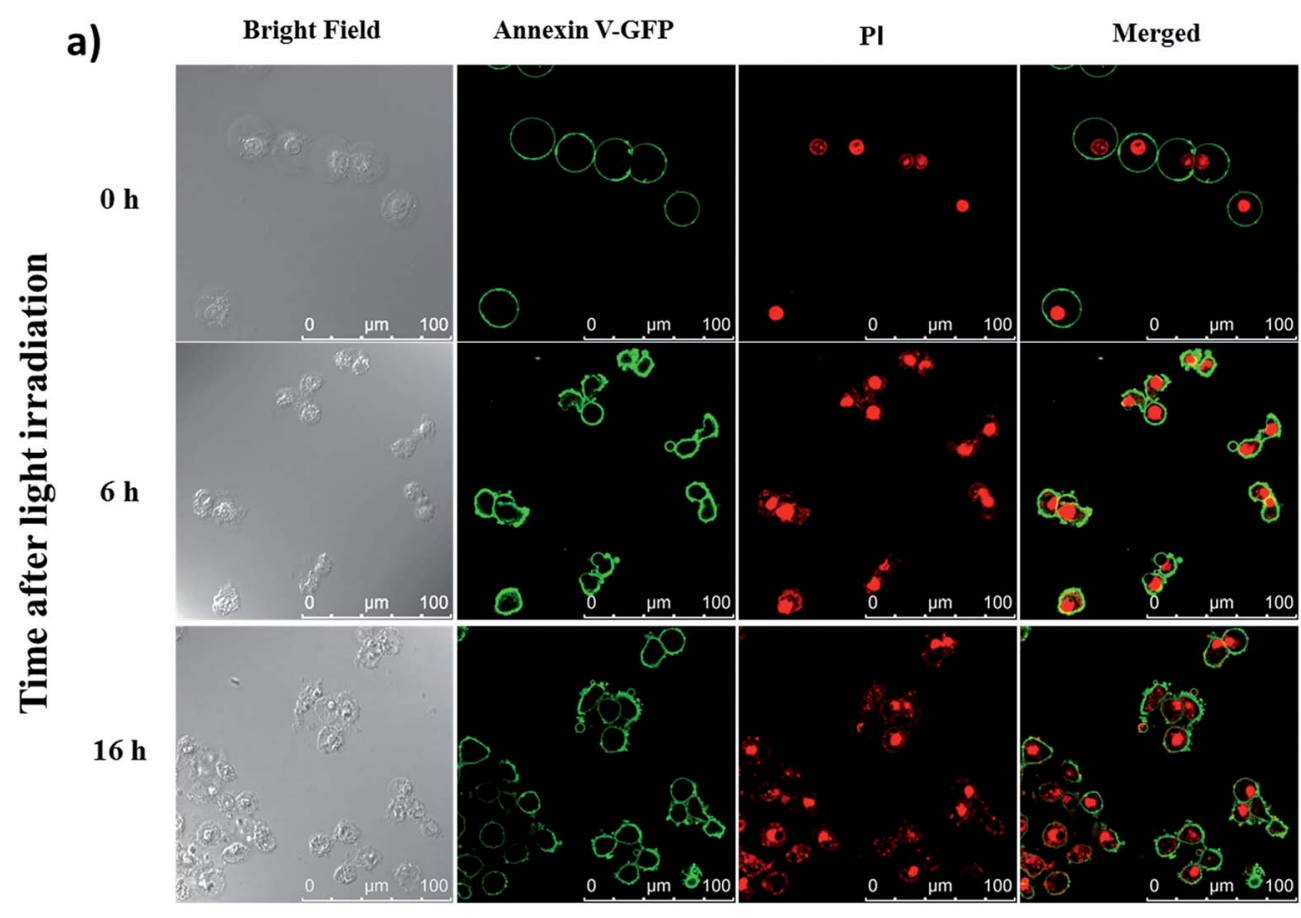

b)

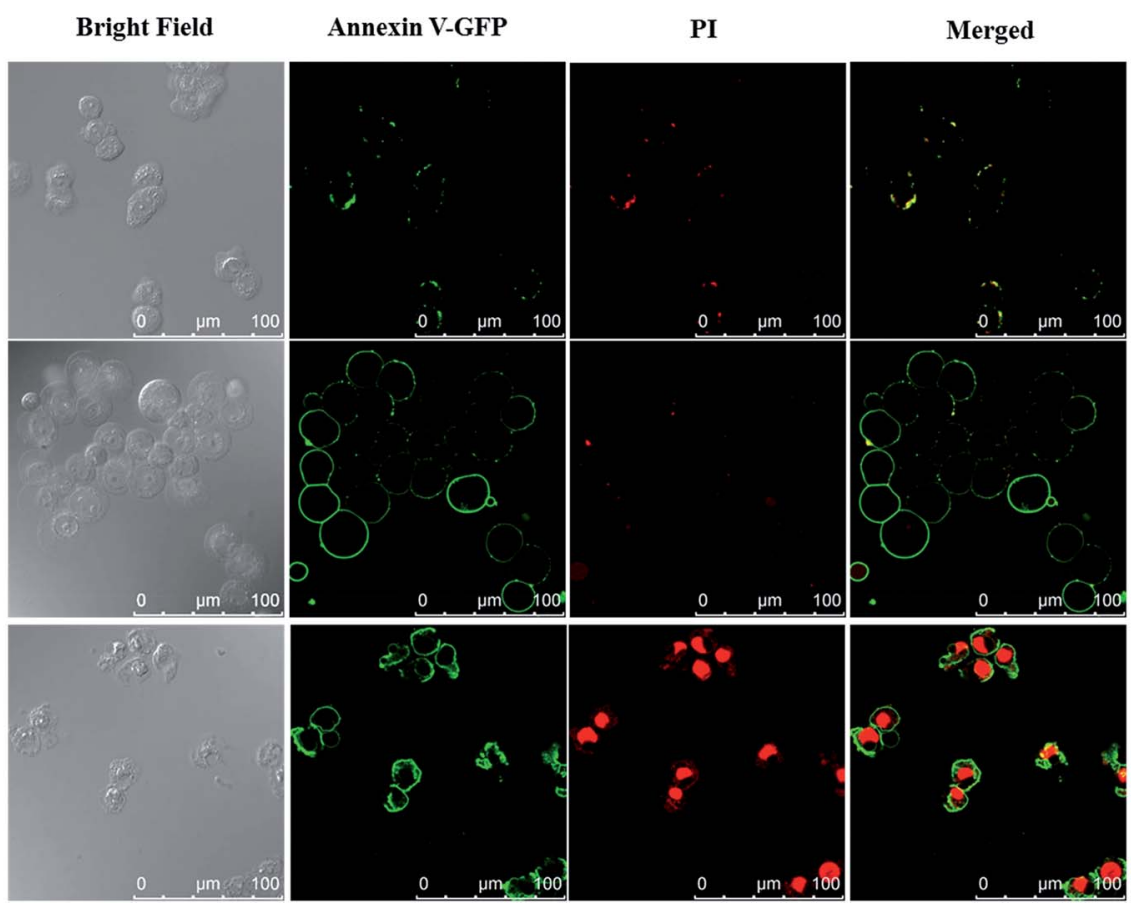

Fig. 7 Confocal microscopic images of HT29 cells after incubation with conjugate 4 for 10 min and light irradiation $\left(\lambda>610 \mathrm{~nm}, 18 \mathrm{~mW} \mathrm{~cm}^{-2}, 20\right.$ $\mathrm{min}$ ) (a) right after drug incubation and (b) $6 \mathrm{~h}$ after drug incubation. The cells were then costained with annexin V-GFP and PI after 0,6 and $16 \mathrm{~h}$. The right-most column shows the merged images of annexin V-GFP (green) and PI (red). 
cytotoxicity upon illumination for both conditions. The $\mathrm{IC}_{50}$ values defined as the dye concentrations required to kill $50 \%$ of the cells $(0.37 \mu \mathrm{M}$ for membrane-based PDT and $0.23 \mu \mathrm{M}$ for lysosome-based PDT) were found to be similar despite the fluorescence intensity on cell membrane after incubation for 10 min was weaker than that inside the cells after further incubation for $6 \mathrm{~h}$ (Fig. S5, ESI $\dagger$ ). It has been reported that PDT initiated at the cell membrane usually causes cell death through necrosis, while apoptosis is a dominant cell-death pathway when the photosensitisers are fully internalised. ${ }^{19}$ The efficiency in cell killing could be different for the two cell-death pathways. In addition, the quenching efficiency for fluorescence emission is usually higher than that for singlet oxygen. ${ }^{20}$ Hence, the photosensitisation at the cell membrane could be as effective as the process inside the cells even though the quenching of fluorescence seems to be higher in the former compartment. These two factors might be able to account for the discrepancy.

It is worth mentioning that the photocytotoxicity of $\mathbf{4}$ is much higher than that of the previously reported peptidephthalocyanine conjugates for EGFR targeting. ${ }^{21}$ Among the four conjugates reported, only the two with the cationic charged peptide sequence LARLLT can target EGFR and be internalised into cancer cells, while the other two GE11-conjugated analogues show poor water solubility, which may be due to the presence of three tert-butyl substituents on the phthalocyanine ring. All the four conjugates are non-toxic $\left(\mathrm{IC}_{50}>100 \mu \mathrm{M}\right)$ against HT29 cells, both in the dark and upon irradiation. The photocytotoxicity of $\mathbf{4}$ also seems to be significantly higher than that of the GE11 conjugate reported by us earlier, ${ }^{17}$ of which the $\mathrm{IC}_{50}$ value against $\mathrm{A} 431$ human epidermoid carcinoma cells was found to be $14 \mu \mathrm{M}$. It is believed that the ionic nature of some of the amino acid residues of $\mathrm{QRH}^{*}$ plays an important role. It can greatly enhance the water solubility and reduce the aggregation of the phthalocyanine core so that the targeting effect would not be affected. This could be the reason why conjugate 4 could rapidly bind to the EGFR on cell surface within $10 \mathrm{~min}$ and induce strong PDT effect.

To reveal the cell-death pathways under the two incubation conditions, annexin V-green fluorescent protein (GFP) and propidium iodide (PI) costaining was performed and monitored using confocal laser scanning microscopy. HT29 cells were first incubated with conjugate 4 for $10 \mathrm{~min}$ under which the compound was mainly confined on the cell surface. After washing and refilling with a drug-free medium, the cells were irradiated with red light for $20 \mathrm{~min}\left(\lambda>610 \mathrm{~nm}, 18 \mathrm{~mW} \mathrm{~cm}^{-2}\right)$ immediately or after further incubation for $6 \mathrm{~h}$ under which the

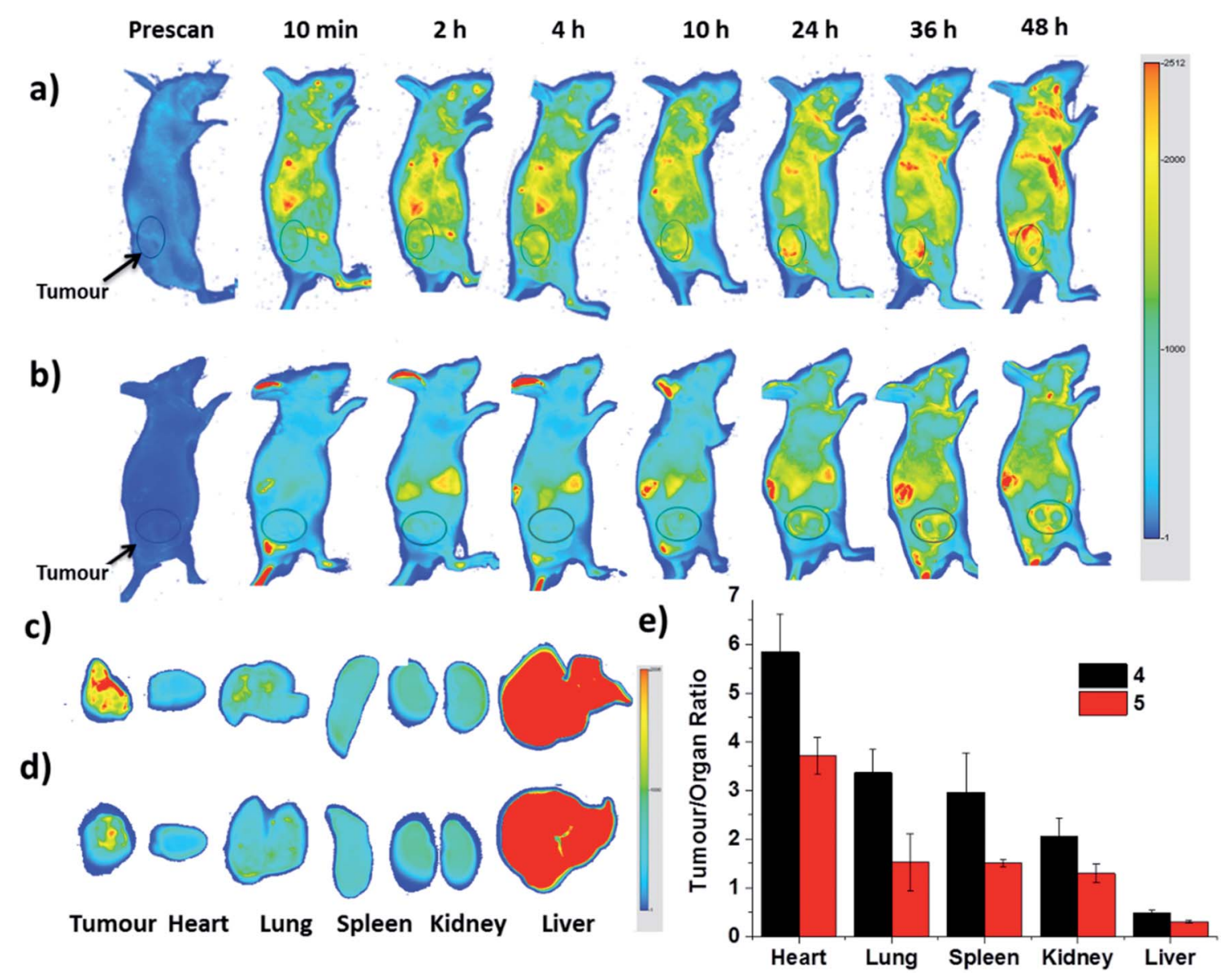

Fig. 8 In vivo near-infrared fluorescence images of HT29 tumour-bearing nude mice after intravenous injection with (a) 4 and (b) 5 over a period of 48 h. (c) and (d) show the corresponding ex vivo images of the tumour and other major organs harvested at $48 \mathrm{~h}$ post-injection. (e) plots the tumour-to-organ ratio for different organs for 4 and 5 at $48 \mathrm{~h}$ post-injection based on their relative fluorescence intensities (per unit area). Data are expressed as the mean \pm standard deviation of four mice in each group. 
dye had been internalised and was mainly localised in lysosomes. The cells were then costained with annexin V-GFP and PI after 0,6 and $16 \mathrm{~h}$, and then visualised using confocal laser scanning microscopy. As shown in Fig. 7a, for the cells being incubated with 4 for $10 \mathrm{~min}$, cell necrosis was observed with most of the cells being stained with annexin V-GFP and PI right after light irradiation. For the cells with $6 \mathrm{~h}$ post-incubation before light irradiation, they could only be stained with annexin V-GFP at $6 \mathrm{~h}$ after light irradiation. After prolonging the incubation time to $16 \mathrm{~h}$ after light irradiation, the cells were able to be stained with both annexin V-GFP and PI, indicating a process of early to late apoptosis (Fig. 7b). ${ }^{22}$ These results demonstrated that when the PDT effect of $\mathbf{4}$ occurred on cell membrane, it induced cell necrosis, while the cells were killed mainly through apoptosis after the drug was internalised into the cells, which further supported the above hypothesis and were consistent with those observed earlier. ${ }^{19}$

\section{In vivo biodistribution}

Finally, the biodistribution of ZnPc-QRH* (4) and ZnPc-EPR* (5) in HT29 tumour-bearing nude mice was monitored using an infrared imaging system over a period of $48 \mathrm{~h}$. It can be seen in Fig. 8a that fluorescence was observed as early as $2 \mathrm{~h}$ after intravenous injection of $\mathbf{4}$, and the intensity in the tumour area was increased along with time. In contrast, for the mice being treated with $\mathbf{5}$, the fluorescence intensity around the tumour remained weak throughout the period (Fig. 8b). To quantify the fluorescence intensities in the tumour and some major organs, the mice were sacrificed after $48 \mathrm{~h}$. The tumour and organs, including heart, lung, spleen, kidney and liver were then harvested, and their relative fluorescence intensities (per unit area) were measured and are reported in tumour/organ ratio (Fig. 8ce). As shown in Fig. 8e, the accumulation of $\mathbf{4}$ in tumour was significantly higher than that in the organs examined (with a tumour/organ ratio ranging from 2 to 6) except the liver (with a tumour/organ ratio $<1$ ). For conjugate 5 with a scrambled sequence, the tumour selectivity was consistently lower for all the organs, indicating that the $\mathrm{QRH}^{*}$-conjugated phthalocyanine 4 does have a higher affinity to HT29 tumour compared with the EPR*-conjugated counterpart 5.

\section{Conclusions}

A zinc(II) phthalocyanine conjugated with a highly hydrophilic

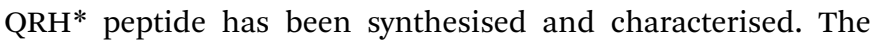
EGFR-targeting effect of this conjugate towards HT29 cells has been validated using a series of in vitro experiments. It has been found that the peptide can promote binding to the cell membrane within $10 \mathrm{~min}$ followed by internalisation after prolonged incubation through receptor-mediated endocytosis, leading to localisation in lysosomes eventually. The cellular uptake of this conjugate towards HT29 cells is significantly higher than that for HEK-293 and HepG2 cells used as the EGFR-negative controls. The conjugate also shows high photocytotoxicity towards HT29 cells with an $\mathrm{IC}_{50}$ value of $c a .0 .2 \mu \mathrm{M}$ with the cell-death pathway depending on its localisation where the PDT process is initiated. Finally, the in vivo imaging analysis has also demonstrated the high affinity of this conjugate to HT29 tumour compared with most major organs. The overall results suggest that $\mathrm{QRH}^{*}$, despite having a short peptide sequence, is a very specific ligand for EGFR and the conjugation of this ligand with a simple phthalocyanine-based photosensitiser can make the resulting conjugate highly promising for targeted PDT.

\section{Experimental}

\section{General}

All reactions were performed under an atmosphere of nitrogen. DMF and $\mathrm{CH}_{2} \mathrm{Cl}_{2}$ were dried using an INERT solvent purification system. Chromatographic purification was performed on silica gel (Macherey-Nagel, 230-400 mesh) with the indicated eluents. Size-exclusion chromatography was carried out on BioBeads S-X1 beads (200-400 mesh) with the indicated eluents. All other solvents and reagents were of reagent grade and used as received. Phthalocyanine $\mathbf{3}$ was prepared as described previously. ${ }^{\mathbf{1 4}}$

MALDI mass spectra were recorded on a Bruker Autoflex Speed MALDI-TOF mass spectrometer. For accurate mass measurements, the lowest $\mathrm{m} / \mathrm{z}$ value of the isotopic envelope was reported and compared with the theoretical value. Electronic absorption and steady-state fluorescence spectra were taken on a Shimadzu UV-1800 UV-Vis spectrophotometer and a Horiba FluoroMax spectrofluorometer respectively. HPLC experiments were performed on an Apollo-C18 column $(5 \mu \mathrm{m}$, $4.6 \mu \mathrm{m} \times 250 \mathrm{~mm})$ or on an XBridge-C18 column $(5 \mu \mathrm{m}, 10 \mu \mathrm{m}$ $\times 250 \mathrm{~mm}$ ) by using a Waters 1525 binary HPLC pump with a Waters 2998 photodiode array detector.

\section{Preparation of 2}

This peptide resin was synthesised manually by using a modified Fmoc solid-phase peptide synthesis (SPPS) protocol with the commercially available $N$ - $\alpha$-Fmoc-protected amino acids. The rink amide resin was used as the solid support, and HATU was used as the carboxyl group activating agent. The swelled resin was treated twice with piperidine (20\%) in DMF for $20 \mathrm{~min}$ before being coupled with the first amino acid Fmoc-Lys(Mtt)$\mathrm{OH}$. An excess of the Fmoc-protected amino acids (4 equiv.), DIPEA (8 equiv.) and HATU (4 equiv.) were then used for each coupling. After the final coupling, the peptide resin was washed with DMF and $\mathrm{CH}_{2} \mathrm{Cl}_{2}$, and then the Mtt side chain protecting group was selectively removed using TFA (1\%) and TIPS (2\%) in $\mathrm{CH}_{2} \mathrm{Cl}_{2}$ with continuous shaking at room temperature for $60 \mathrm{~min}$. The deprotection was repeated once to ensure successful removal of the Mtt protecting group. To check the purity of the peptide, a portion of the peptide resin was treated with a solution $(0.5 \mathrm{~mL})$ containing a mixture of TFA $(95 \%)$, TIPS $(2.5 \%)$ and $\mathrm{H}_{2} \mathrm{O}(2.5 \%)$ for $2 \mathrm{~h}$ to cleave the peptide from the resin and remove the protecting groups. The resin was removed by filtration and the filtrate was precipitated by the addition of diethyl ether. After centrifugation, the supernatant was removed. The yellow solid obtained was redissolved in DMF 
$(0.2 \mathrm{~mL})$ and then precipitated again by the addition of diethyl ether. This purification procedure was repeated twice and the product was dried in vacuo before HPLC analysis.

\section{Preparation of 4}

A mixture of $3(10 \mathrm{mg}, 14.0 \mu \mathrm{mol})$, DIPEA $(20 \mu \mathrm{L}, 112.0 \mu \mathrm{mol})$ and HATU $(22 \mathrm{mg}, 56 \mu \mathrm{mol})$ in DMF $(4 \mathrm{~mL})$ was added to the peptide resin 2 . The mixture was shaken overnight at room temperature. The Fmoc protecting group at the N-terminal was then removed from the resin with piperidine (20\%) in DMF, and then the dark-green resin was washed with DMF and $\mathrm{CH}_{2} \mathrm{Cl}_{2}$. The resin was then treated with a solution $(2 \mathrm{~mL})$ containing TFA (95\%), TIPS (2.5\%) and $\mathrm{H}_{2} \mathrm{O}(2.5 \%)$ for $2 \mathrm{~h}$ to remove all the protecting groups on the peptide sequence and cleave the peptide from the resin. The resin was removed by filtration and the filtrate was precipitated by the addition of diethyl ether. After centrifugation, the supernatant was removed. The green solid obtained was redissolved in DMF $(0.5 \mathrm{~mL})$, and then precipitated by the addition of diethyl ether. This purification procedure was repeated three times and the product was lyophilised before HPLC purification. The purity of the conjugate 4 was found to be $>95 \%$ by HPLC analysis (Fig. S1a, ESI $\dagger$ ). MS (MALDI-TOF): an isotopic cluster with the lowest $\mathrm{m} / \mathrm{z}$ value calculated for $\mathrm{C}_{95} \mathrm{H}_{114} \mathrm{~N}_{32} \mathrm{O}_{20} \mathrm{Zn}[\mathrm{M}+\mathrm{H}]^{+}$2087.825; found: 2087.828 (Fig. S1b, ESI†).

\section{Preparation of 5}

This conjugate with a scrambled sequence EPR* was prepared in the same way as 4 described above. The purity of this conjugate was found to be $>95 \%$ by HPLC analysis (Fig. S2a, ESI $\dagger$ ). MS (MALDI-TOF): an isotopic cluster with the lowest $\mathrm{m} / \mathrm{z}$ value calculated for $\mathrm{C}_{95} \mathrm{H}_{114} \mathrm{~N}_{32} \mathrm{O}_{20} \mathrm{Zn}[\mathrm{M}+\mathrm{H}]^{+} 2087.825$; found: 2087.822 (Fig. S2b, ESI $\dagger$ ).

\section{Determination of fluorescence quantum yields $\left(\Phi_{\mathrm{F}}\right)$}

The values of $\Phi_{\mathrm{F}}$ were determined by the equation $\Phi_{\mathrm{F}}(\mathrm{s})=\left(F_{\mathrm{s}}\right)$ $\left.F_{\text {ref }}\right)\left(A_{\text {ref }} / A_{\mathrm{s}}\right)\left(n_{\mathrm{s}}{ }^{2} / n_{\text {ref }}{ }^{2}\right) \Phi_{\mathrm{f}}($ ref $),{ }^{23}$ where subscript $\mathrm{s}$ refers to the sample solutions and ref stands for the reference. $F, A$ and $n$ are the measured fluorescence (area under the emission peak), the absorbance at the excitation position $(610 \mathrm{~nm})$ and the refractive index of the solvent respectively. ZnPc in DMF was used as the reference $\left[\Phi_{\mathrm{f}}(\right.$ ref $\left.)=0.28\right] .^{15}$

\section{Determination of singlet oxygen quantum yields $\left(\Phi_{\Delta}\right)$}

The values of $\Phi_{\Delta}$ were calculated by using ZnPc in DMF as reference $\left(\Phi_{\Delta}=0.56\right)^{16}$ and DPBF as the singlet oxygen scavenger. A solution of DPBF $(30 \mu \mathrm{M})$ and the sample $(2 \mu \mathrm{M})$ in DMF was irradiated with red light from a $100 \mathrm{~W}$ halogen lamp after passing through a water tank for cooling and a colour filter with cut-on wavelength at $610 \mathrm{~nm}$ (Newport). The absorption maximum of DPBF at $417 \mathrm{~nm}$ was monitored along with time. The $\Phi_{\Delta}$ values were calculated according to the equation $\Phi_{\Delta}(\mathrm{s})=$ $\Phi_{\Delta}($ ref $)\left(W_{\mathrm{s}} I_{\text {ref }}\right) /\left(W_{\text {ref }} I_{\mathrm{s}}\right)$, where $\Phi_{\Delta}($ ref $)$ is the $\Phi_{\Delta}$ of ZnPc in DMF, $W_{\mathrm{s}}$ and $W_{\text {ref }}$ are the DPBF photobleaching rates in the presence of the sample and ZnPc respectively, and $I_{\mathrm{s}}$ and $I_{\text {ref }}$ are the rates of light absorption by the sample and ZnPc respectively.

\section{Cell lines and culture conditions}

HT29 human colorectal adenocarcinoma cells (ATCC, no. HTB38) were maintained in Roswell Park Memorial Institute (RPMI) 1640 medium (Invitrogen, no. 23400-021) supplemented with fetal bovine serum (10\%; ThermoFisher Scientific, cat. no. 10270-106) and penicillin-streptomycin solution (100 units per $\mathrm{mL}$ and $100 \mathrm{mg} \mathrm{mL} \mathrm{m}^{-1}$ respectively). HepG2 human hepatocellular carcinoma cells (ATCC, no. HB-8065) and HEK-293 human embryonic kidney cells (ATCC CRL-1573) were maintained in Dulbecco's modified Eagle medium (DMEM) (ThermoFisher Scientific, cat. no. 12100-046) supplemented with fetal bovine serum (10\%) and penicillin-streptomycin solution (100 units per $\mathrm{mL}$ and $100 \mu \mathrm{g} \mathrm{mL}{ }^{-1}$ respectively). All the cells were grown at $37{ }^{\circ} \mathrm{C}$ in a humidified $5 \% \mathrm{CO}_{2}$ atmosphere.

\section{Confocal fluorescence microscopic studies}

Approximately $2 \times 10^{5}$ HT29 cells in RPMI medium $(2 \mathrm{~mL})$ or HepG2 or HEK-293 cells in DMEM medium $(2 \mathrm{~mL})$ were seeded on a confocal dish and incubated overnight at $37{ }^{\circ} \mathrm{C}$ with $5 \%$ $\mathrm{CO}_{2}$. After removal of the medium, the cells were incubated with corresponding drugs. The medium was then removed and the cells were rinsed with PBS before being viewed with a Leica TCS SP8 high speed confocal microscope equipped with a solid-state $638 \mathrm{~nm}$ laser. The ZnPc was excited at $638 \mathrm{~nm}$ and monitored at 650-750 nm. The images were digitised and analysed using a Leica Application Suite X software.

\section{Study of subcellular localisation}

HT29 cells on glass-bottom dishes of $35 \mathrm{~mm}$ diameter (MatTek Corporation, P35G-0-14-C) were incubated in the culture medium with $4(2 \mu \mathrm{M})$ for $10 \mathrm{~min}$ at $37^{\circ} \mathrm{C}$. After being washed twice with PBS, the cells were refed with $2 \mathrm{~mL}$ of the culture medium and incubated for $6 \mathrm{~h}$, and then stained with $0.2 \mu \mathrm{M}$ ER-Tracker green (Thermo Fisher Scientific Inc., E34251), 0.2 $\mu \mathrm{M}$ MitoTracker Green FM (Thermo Fisher Scientific Inc., M7514) or $2 \mu \mathrm{M}$ LysoTracker Green DND-26 (Thermo Fisher Scientific Inc., L7526) in Hank's Balanced Salt Solution (HBSS) at $37^{\circ} \mathrm{C}$ for 15,15 and $30 \mathrm{~min}$ respectively. After being washed twice with PBS, the cells were refed with HBSS and observed using a Leica TCS SP8 high speed confocal microscope equipped with a $488 \mathrm{~nm}$ argon laser and a $633 \mathrm{~nm}$ laser. All the trackers were excited at $488 \mathrm{~nm}$, and their fluorescence was monitored at 500-570 nm, while conjugate 4 was excited at $638 \mathrm{~nm}$ and its fluorescence was monitored at 650-760 $\mathrm{nm}$.

\section{Study of photocytotoxicity}

Approximately $1 \times 10^{4}$ HT29 cells per well in the culture medium were inoculated in 96-multiwell plates and incubated overnight at $37{ }^{\circ} \mathrm{C}$ in a humidified $5 \% \mathrm{CO}_{2}$ atmosphere. The conjugate 4 was first dissolved in dimethylsulfoxide (DMSO), and this stock solution was then diluted to respective concentrations with the culture medium. The cells were incubated with 
$100 \mu \mathrm{L}$ of these drug solutions for $10 \mathrm{~min}$ at $37{ }^{\circ} \mathrm{C}$ under $5 \%$ $\mathrm{CO}_{2}$. The cells were then rinsed again with PBS, refed with 100 $\mu \mathrm{L}$ of the culture medium and incubated for 0 or $6 \mathrm{~h}$ before being illuminated at ambient temperature. The light source consisted of a $300 \mathrm{~W}$ halogen lamp, a water tank for cooling and a coloured glass filter (Newport) cut-on at $\lambda=610 \mathrm{~nm}$. The fluence rate $(\lambda>610 \mathrm{~nm})$ was $18 \mathrm{~mW} \mathrm{~cm} \mathrm{~cm}^{-2}$. Illumination of $20 \mathrm{~min}$ led to a total fluence of $22 \mathrm{~J} \mathrm{~cm}^{-2}$. Cell viability was determined by means of the colourimetric MTT assay. ${ }^{24}$ After illumination, the cells were incubated at $37{ }^{\circ} \mathrm{C}$ under $5 \% \mathrm{CO}_{2}$ for $16 \mathrm{~h}$. A MTT (Sigma) solution in PBS $\left(3 \mathrm{mg} \mathrm{mL}{ }^{-1}, 50 \mu \mathrm{L}\right)$ was added to each well followed by incubation for $4 \mathrm{~h}$ under the same environment. DMSO $(70 \mu \mathrm{L})$ was then added to each well. Solutions in all wells were mixed until homogenous. Absorbance at $490 \mathrm{~nm}$ was measured using a plate reader (Tecan Spark 10M Microplate Reader). The average absorbance of the blank wells, which did not contain the cells, was subtracted from the readings of the other wells. The cell viability was then determined by the equation: $\%$ viability $=\left[\left(\sum A_{\mathrm{i}} / A_{\text {control }} \times 100\right)\right] /$ $n$, where $A_{\mathrm{i}}$ is the absorbance of the $i^{\text {th }}$ datum $(i=1,2 \ldots n)$, $A_{\text {control }}$ is the average absorbance of the control wells, in which the conjugate was absent and $n(=4)$ is the number of data points. The percentages of cell viabilities in the cytotoxicity experiments were used as the quantitative expression of the effect of the drugs.

\section{Annexin V-GFP/PI costaining assay}

HT-29 cells on glass-bottom dishes of $35 \mathrm{~mm}$ diameter (MatTek Corporation, P35G-0-14-C) were incubated in RPMI medium with $4(0.5 \mu \mathrm{M})$ for $10 \mathrm{~min}$ at $37^{\circ} \mathrm{C}$. After being washed twice with PBS, the cells were refed with $2 \mathrm{~mL}$ of RPMI medium with or without further incubation for $6 \mathrm{~h}$, followed by light irradiation $\left(18 \mathrm{~mW} \mathrm{~cm}^{-2}, 20 \mathrm{~min}\right)$. After that, the cells were further incubated at $37{ }^{\circ} \mathrm{C}$ under $5 \% \mathrm{CO}_{2}$ for 0,6 or $16 \mathrm{~h}$ and then strained with Annexin V-GFP and PI in binding buffer for $15 \mathrm{~min}$ before visualisation with confocal fluorescence microscopy. The probes were excited at $488 \mathrm{~nm}$, and the fluorescence was monitored at 500-530 nm (Annexin V-GFP) and 570-680 nm (PI).

\section{In vivo imaging analysis}

Female Balb/c nude mice (20-25 g) were obtained from the Laboratory Animal Services Centre at The Chinese University of Hong Kong. All experiments involving live animals were performed in strict accordance with the animal experimentation guidelines and were approved by the Animal Experimentation Ethics Committee of the University (ref. no. 14-044-GRF). Licence to conduct animal experiments was obtained from the Department of Health, Government of the Hong Kong Special Administrative Region. The mice were kept under pathogen-free conditions with free access to food and water. HT29 cells (about $1 \times 10^{7}$ cells in $200 \mu \mathrm{L}$ HBSS) were inoculated subcutaneously on the back of the mice. Once the tumours had grown to a size of $60-100 \mathrm{~mm}^{3}, 40 \mathrm{nmol}$ of conjugates 4 and 5 were first dissolved in $400 \mu \mathrm{L}$ distilled water containing $1 \%$ DMSO respectively. These solutions ( $200 \mu \mathrm{L}$, equivalent to $20 \mathrm{nmol}$ of 4 or 5) were injected into the tumour-bearing mice through tail intravenous injection. In vivo fluorescence imaging was captured before and after the injection (at different time points up to 48 h) with an Odyssey infrared imaging system (excitation wavelength $=680 \mathrm{~nm}$, emission wavelength $\geq 700 \mathrm{~nm}$ ). The images were digitised and analysed by use of the Odyssey imaging system software (9201-500). After in vivo imaging studies, the animals were euthanised at 48 post-injection. Tumours and other major organs were harvested and their fluorescence intensities were measured. Four mice were used for each conjugate.

\section{Conflicts of interest}

There are no conflicts to declare.

\section{Acknowledgements}

This work was supported by a grant from the Research Grants Council of the Hong Kong Special Administrative Region (Ref. No. 14303814).

\section{References}

1 (a) K. P. Loh, D. Ho, G. N. C. Chiu, D. T. Leong, G. Pastorin and E. K. H. Chow, Adv. Mater., 2018, 30, 1802368; (b) B. del Rosal, B. Jia and D. Jaque, Adv. Funct. Mater., 2018, 28, 1803733; (c) J. Li and K. Pu, Chem. Soc. Rev., 2019, 48, 38-71; (d) C. N. Ko, G. Li, C. H. Leung and D. L. Ma, Coord. Chem. Rev., 2019, 381, 79-103.

2 (a) F. Hu, S. Xu and B. Liu, Adv. Mater., 2018, 30, 1801350; (b) S. Jung and X. Chen, Adv. Healthcare Mater., 2018, 7, 1800252; (c) S. He, J. Song, J. Qu and Z. Cheng, Chem. Soc. Rev., 2018, 47, 4258-4278.

3 (a) D. E. J. G. J. Dolmans, D. Fukumura and R. K. Jain, Nat. Rev. Cancer, 2003, 3, 380-387; (b) S. B. Brown, E. A. Brown and I. Walker, Lancet Oncol., 2004, 5, 497-508; (c) D. van Straten, V. Mashayekhi, H. S. de Bruijn, S. Oliveira and D. J. Robinson, Cancers, 2017, 9, 19; (d) X. Li, N. Kwon, T. Guo, Z. Liu and J. Yoon, Angew. Chem., Int. Ed., 2018, 57, 11522-11531; (e) S. Monro, K. L. Colón, H. Yin, J. Roque III, P. Konda, S. Gujar, R. P. Thummel, L. Lilge, C. G. Cameron and S. A. McFarland, Chem. Rev., 2019, 119, 797-828.

4 (a) C. Mao, Y. Xiang, X. Liu, Y. Zheng, K. W. K. Yeung, Z. Cui, X. Yang, Z. Li, Y. Liang, S. Zhu and S. Wu, ACS Appl. Mater. Interfaces, 2019, 11, 17902-17914; (b) J.-f. Lin, J. Li, A. Gopal, T. Munshi, Y.-w. Chu, J.-x. Wang, T.-t. Liu, B. Shi, X. Chen and L. Yan, Chem. Commun., 2019, 55, 2656-2659.

5 A. P. Castano, P. Mroz and M. R. Hamblin, Nat. Rev. Cancer, 2006, 6, 535-545.

6 M. Lan, S. Zhao, W. Liu, C.-S. Lee, W. Zhang and P. Wang, Adv. Healthcare Mater., 2019, 1900132.

7 (a) D. K. P. Ng, Future Med. Chem., 2014, 6, 1991-1993; (b) R. C. H. Wong, P.-C. Lo and D. K. P. Ng, Coord. Chem. Rev., 2019, 379, 30-46; (c) X. Li, B.-D. Zheng, X.-H. Peng, S.-Z. Li, 
J.-W. Ying, Y. Zhao, J.-D. Huang and J. Yoon, Coord. Chem. Rev., 2019, 379, 147-160.

8 (a) R. C. H. Wong, S. Y. S. Chow, S. Zhao, W.-P. Fong, D. K. P. Ng and P.-C. Lo, ACS Appl. Mater. Interfaces, 2017, 9, 23487-23496; (b) Y. Sun, H. Hu, N. Zhao, T. Xia, B. Yu, C. Shen and F.-J. Xu, Biomaterials, 2017, 117, 77-91; (c) D. Gao and P.-C. Lo, J. Controlled Release, 2018, 282, 46-61; (d) J. Ma, D. Chen, Y. Li, Y. Chen, Q. Liu, X. Zhou, K. Qian, Z. Li, H. Ruan, Z. Hou and X. Zhu, J. Controlled Release, 2018, 284, 1-14; (e) C. Jiang, R. Wang, H. Ou, A. Li, Y. An, S. Guo and L. Shi, Chem. Commun., 2018, 54, 3985-3988; $(f)$ J. Wang, X. Zhuo, X. Xiao, R. Mao, Y. Wang, J. Wang and J. Liu, Nanoscale, 2019, 11, 3386-3395.

9 (a) C. Zhang, W. Wu, R. Q. Li, W. X. Qiu, Z. N. Zhuang, S. X. Cheng and X. Z. Zhang, Adv. Funct. Mater., 2018, 28, 1804492; (b) V. Almeida-Marrero, E. van de Winckel, E. Anaya-Plaza, T. Torres and A. de la Escosura, Chem. Soc. Rev., 2018, 47, 7369-7400.

10 M.-R. Ke, S.-L. Yeung, W.-P. Fong, D. K. P. Ng and P.-C. Lo, Chem.-Eur. J., 2012, 18, 4225-4233.

11 S. Kopetz, Nat. Rev. Gastroenterol. Hepatol., 2019, 16, 79-80. 12 (a) Z. Li, R. Zhao, X. Wu, Y. Sun, M. Yao, J. Li, Y. Xu and J. Gu, FASEB J., 2005, 19, 1978-1985; (b) P. L. Hsiung, J. Hardy, S. Friedland, R. Soetikno, C. B. Du, A. P. Wu, P. Sahbaie, J. M. Crawford, A. W. Lowe and T. D. Wang, Nat. Med., 2008, 14, 454-458; (c) S. Song, D. Liu, J. Peng, H. Deng, Y. Guo, L. X. Xu, A. D. Miller and Y. Xu, FASEB J., 2009, 23, 1396-1404; (d) J. Burggraaf, I. M. C. Kamerling, P. B. Gordon, L. Schrier, M. L. de Kam, A. J. Kales, R. Bendiksen, B. Indrevoll, R. M. Bjerke, S. A. Moestue, S. Yazdanfar, A. M. J. Langers, M. Swaerd-Nordmo, G. Torheim, M. V. Warren, H. Morreau, P. W. Voorneveld, T. Buckle, F. W. B. van Leeuwen, L. I. Ødegårdstuen, G. T. Dalsgaard, A. Healey and J. C. H. Hardwick, Nat.
Med., 2015, 21, 955-961; (e) J. Zhou, B. P. Joshi, X. Duan, A. Pant, Z. Qiu, R. Kuick, S. R. Owens and T. D. Wang, Clin. Transl. Gastroenterol., 2015, 6, e101.

13 A. R. Sepulveda, S. R. Hamilton, C. J. Allegra, W. Grody, A. M. Cushman-Vokoun, W. K. Funkhouser, S. E. Kopetz, C. Lieu, N. M. Lindor, B. D. Minsky, F. A. Monzon, D. J. Sargent, V. M. Singh, J. Willis, J. Clark, C. Colasacco, R. B. Rumble, R. Temple-Smolkin, C. B. Ventura and J. A. Nowak, Am. J. Clin. Pathol., 2017, 147, 221-260.

14 R. C. H. Wong, D. K. P. Ng, W.-P. Fong and P.-C. Lo, Chem.Eur. J., 2017, 23, 16505-16515.

15 I. Scalise and E. N. Durantini, Bioorg. Med. Chem., 2005, 13, 3037-3045.

16 M. D. Maree, N. Kuznetsova and T. Nyokong, J. Photochem. Photobiol., A, 2001, 140, 117-125.

17 L. Yu, Q. Wang, R. C. H. Wong, S. Zhao, D. K. P. Ng and P.-C. Lo, Dyes Pigm., 2019, 163, 197-203.

18 (a) F. Zhang, S. Wang, L. Yin, Y. Yang, Y. Guan, W. Wang, H. Xu and N. Tao, Anal. Chem., 2015, 87, 9960-9965; (b) Q. Zhou, Z. Li, J. Zhou, B. P. Joshi, G. Li, X. Duan, R. Kuick, S. R. Owens and T. D. Wang, Photoacoustics, 2016, 4, 43-54.

19 P. Mroz, A. Yaroslavsky, G. B. Kharkwal and M. R. Hamblin, Cancers, 2011, 3, 2516-2539.

20 J. F. Lovell, J. Chen, M. T. Jarvi, W. G. Cao, A. D. Allen, Y. Liu, T. T. Tidwell, B. C. Wilson and G. Zheng, J. Phys. Chem. B, 2009, 113, 3203-3211.

21 B. G. Ongarora, K. R. Fontenot, X. Hu, I. Sehgal, S. D. Satyanarayana-Jois and M. G. H. Vicente, J. Med. Chem., 2012, 55, 3725-3738.

22 G. Majno and I. Joris, Am. J. Pathol., 1995, 146, 3-15.

23 D. F. Eaton, Pure Appl. Chem., 1988, 60, 1107-1114.

24 H. Tada, O. Shiho, K. Kuroshima, M. Koyama and

K. Tsukamoto, J. Immunol. Methods, 1986, 93, 157-165. 